\title{
BAYESIAN HIGHEST POSTERIOR DENSITY INTERVALS FOR THE AVAILABILITY OF A SYSTEM WITH A 'REST-PERIOD' FOR THE REPAIR FACILITY
}

\author{
VSS Yadavalli, A Bekker, PJ Mostert* \& M Botha \\ Department of Statistics \\ University of South Africa \\ *Department of Statistics and Actuarial Science \\ University of Stellenbosch
}

\begin{abstract}
In this paper Bayesian estimation for the steady state availability of a one-unit system with a rest-period for the repair facility is studied. The assumption is that the repair facility takes rest with probability $p$ after each repair completion and the facility does not take the same with probability $(l-p)$. The prior information is assumed to be vague and the Jeffreys' prior is used for the unknown parameters in the system. Gibbs sampling is used to derive the posterior distribution of the availability and subsequently the highest posterior density (HPD) intervals. A numerical example illustrates these results.
\end{abstract}

\section{OPSOMMING}

In hierdie artikel word die Bayes-beraming van die ewewigstoestandsbeskikbaarheid van 'n stelsel wat afwisselend gebruik word, voorgestel. Daar word veronderstel dat die herstelfasiliteit na voltooiing van elke herstel of 'n rustydperk binnegaan of nie. Die rustydperk sal geneem word met waarskynlikheid $p$ en die waarskynlikheid dat daar nie 'n rustydperk geneem word nie, is $(l-p)$. Jeffrey se a priori-verdeling word vir die onbekende parameters in die stelsel aanvaar. Gibbs-steekproefneming word gebruik om die a posterioriverdeling van die beskikbaarheid en daarna die hoogste a posteriori-digtheidsintervalle (HPD) af te lei. 'n Numeriese voorbeeld illustreer hierdie resultate. 


\section{INTRODUCTION}

To evaluate the effectiveness of a system, several concepts have been introduced: maintainability, serviceability, repairability and availability etc. (Kapur \& Lamberson, 1977). Within availability itself, several measures have been proposed. In the past, nine different kinds of availability have been defined (Brender, 1968a, b). The survey of different approaches of availability is available in Lie. et al (1977), and Kumar and Agarwal (1980). Pointwise availability $A(t)$ is, undoubtedly, the most important of these since it gives the probability that the system is functioning at time $t$ (Klassen \& Van Peppen, 1989). Its limit value, when it exists, is called the steady-state or asymptotic availability (Pham-Gia \& Turkkan, 1999). $A_{\infty}$ is defined as the expected fraction of time that the system operates satisfactorily in the long run.

Most of the models studied in the literature have the assumption that the repair facility is continuously available to attend the repair of the failed units. But it is reasonable to expect that a 'rest-period' might be needed to get the repair facility ready for the next repair could be taken up (Subramanian \& Sarma, 1981). This rest-period usually starts after each repair completion. In this paper it is assumed that the 'rest-period' is taken with probability $p$, and will continue with the repairs of the unit with probability $(I-p)$, depending on the amount of time spent by the repair facility.

The Bayesian framework for statistics and decision theory (Bernardo \& Smith, 2000) offers great opportunities for applications in reliability problems (Martz \& Waller, 1982), because of the possibility to take expert knowledge into account through the prior distribution for an assumed parametric model. In this paper the steady state availability of a one unit system as studied by Yadavalli et al (2001) is considered from a Bayesian viewpoint with emphasis on the use of a Jeffreys' prior distribution for the parameters.

Section 2 gives the necessary notation, a brief description of the model and maximum likelihood estimators of the steady state availability as derived by Yadavalli et al (2001). The Bayesian approach to this problem is introduced in section 3, followed by a numerical example illustrating the posterior analysis using the Gibbs sampling method.

\section{ASSUMPTIONS AND SYSTEM DESCRIPTION}

The following characteristics and assumptions describe the model:

(1) The system consists of a unit and a single repair facility.

(2) The lifetime and repair time of the unit are exponentially distributed with parameters $\lambda$ and $\mu$ respectively.

(3) The unit is as good as new after each repair.

(4) Switch is perfect and switchover is instantaneous.

(5) The repair facility is not available for a random time, called rest-period, which is distributed exponentially with parameter $d$. The rest-period $(D)$ is a Bernoulli random variable, which is defined as follows: 


$$
D=\left\{\begin{array}{lll}
1 & \text { with probability } & p \\
0 & \text { with probability } & (1-p)
\end{array}\right.
$$

The states 1 and 0 represent respectively the realisation or not of the "restperiod'.

Let the stochastic process $\{W(t), t \geq 0\}$ with state space $\{0,1,2,3\}$ describe the behaviour of the system at time $t$. The system transitions for the model are given below.

Table 1: System transitions

\begin{tabular}{|c|c|c|}
\hline & \multicolumn{2}{|c|}{ State of the } \\
\hline State number & Unit & repair facility \\
\hline 0 & operable & available \\
\hline 1 & under repair & available \\
\hline 2 & operable & not available \\
\hline 3 & waiting for repair & not available \\
\hline
\end{tabular}

The steady state probabilities can be determined by using the principle of flow-balance (Ravindran et al, 1987). The steady state availability is obtained in Yadavalli et al (2001), namely

$$
A_{\infty}=\frac{\mu d(\lambda+d)}{d^{2} \lambda+d^{2} \mu+\lambda^{2} d+\lambda d \mu+\lambda^{2} \mu p}
$$

Let $X_{1}, X_{2}, \ldots, X_{n}$ and $Y_{1}, Y_{2}, \ldots, Y_{n}$ be random samples of size $n$, each drawn from different exponential populations with failure and repair rates of the unit $\lambda$ and $\mu$ respectively. Also, let $Z_{1}, Z_{2}, \ldots, Z_{n}$ be a random sample of size $n$, drawn from a different exponential population with parameter $d$. The Maximum Likelihood Estimator (MLE) of $A_{\infty}$ is given by (see Yadavalli et al, 2001).

$$
\hat{A}_{\infty}=\frac{\bar{X}(\bar{X}+\bar{Z})}{\left(\bar{X}^{2}+\bar{X} \bar{Y}+p \bar{Z}^{2}+\bar{Y} \bar{Z}+\bar{X} \bar{Z}\right)}
$$

where $\bar{X}=\frac{1}{n} \sum_{j=1}^{n} x_{j}, \quad \bar{Y}=\frac{1}{n} \sum_{j=1}^{n} y_{j}$ and $\bar{Z}=\frac{1}{n} \sum_{j=1}^{n} z_{j}$.

Let $\theta=\left(\theta_{1}, \theta_{2}, \theta_{3}\right)$ with

$$
\theta_{i}=\frac{1}{\lambda}, \theta_{2}=\frac{1}{\mu}, \theta_{3}=\frac{1}{d}
$$


The steady state availability given in (3) reduces to

$$
A_{\infty}=\frac{\theta_{1}\left(\theta_{1}+\theta_{3}\right)}{\theta_{1} \theta_{2}+\theta_{1}^{2}+\theta_{2} \theta_{3}+\theta_{1} \theta_{3}+p \theta_{3}^{2}}
$$

The ( $1-\alpha) \%$ asymptotic confidence limits for $A_{\infty}$ are given by

$$
\hat{A}_{\infty} \pm k_{\frac{\alpha}{2}} \frac{\hat{\sigma}}{\sqrt{n}}
$$

where $\hat{\sigma}^{2}$ is a consistent estimator for $\sigma^{2}(\theta)=\sum_{j=1}^{3}\left(\frac{\partial A_{\infty}}{\partial \theta_{j}}\right)^{2} \theta_{j}^{2}$, and $k_{\frac{\alpha}{2}}$ is obtained from the standardised normal tables.

\section{BAYESIAN INFERENCE OF $A_{\infty}$}

Based on the attributed data, the likelihood function is given by

$$
\begin{aligned}
L\left(\lambda, \mu, \mathrm{d} \mid \mathrm{T}_{1}, \mathrm{~T}_{2}, \mathrm{~T}_{3}\right) & =\prod_{j=1}^{n} \lambda e^{-\lambda x_{j}} \cdot \prod_{j=1}^{n} \mu e^{-\mu \mathrm{y}_{j}} \cdot \prod_{j=1}^{n} d e^{-d z_{j}} \\
& =(\lambda \mu \mathrm{d})^{n} e^{\left(\lambda \mathrm{T}_{1}+\mu \mathrm{T}_{2}+\mathrm{d \textrm {d } _ { 3 } )}\right.}
\end{aligned}
$$

where

$$
\left(T_{1}=\sum_{j=1}^{n} x_{j}, \quad T_{2}=\sum_{j=1}^{n} y_{j}, \quad T_{3}=\sum_{j=1}^{n} z_{j}\right)
$$

is sufficient for $(\lambda, \mu, d)$.

Representing (6) in terms of corresponding mean life time, mean repair time, mean rest-period time, (6) results in (see (3))

$$
L\left(\theta_{1}, \theta_{2}, \theta_{3} \mid T_{1}, T_{2}, T_{3}\right)=\left(\theta_{1} \theta_{2} \theta_{3}\right)^{-n} e^{-\left(\frac{1}{\theta_{1}} T_{1}+\frac{1}{\theta_{2}} T_{2}+\frac{1}{\theta_{3}} T_{3}\right)}
$$

The Jeffreys' prior distribution for $\left(\theta_{1}, \theta_{2}, \theta_{3}\right)$ (see Box \& Tiao, 1992) is given by

$$
g\left(\theta_{1}, \theta_{2}, \theta_{3}\right) \propto \frac{1}{\left(\theta_{1} \theta_{2} \theta_{3}\right)}, \quad \theta_{j}>0(j=1,2,3)
$$

The joint posterior distribution, according to Bayes' theorem (using (7) and (8)) is defined by 


$$
g\left(\theta_{1}, \theta_{2}, \theta_{3} \mid T_{1}, T_{2}, T_{3}\right) \propto\left(\theta_{1} \theta_{2} \theta_{3}\right)^{-n-1} e^{-\left(\frac{1}{\theta_{1}} T_{1}+\frac{1}{\theta_{2}} \cdot T_{2}+\frac{1}{\theta_{3}} T_{3}\right)}
$$

From (9), the joint posterior of $\left(\theta_{1}, A_{\infty}, \theta_{3}\right)$ is given by

$$
g\left(\theta_{1}, A_{\infty}, \theta_{3} \mid \mathrm{T}_{1}, \mathrm{~T}_{2}, \mathrm{~T}_{3}\right)=g\left(\theta_{1}, \theta_{1}\left(\frac{1}{A_{\infty}}-A_{\infty}\right)-\frac{p \theta_{3}^{2}}{\left(\theta_{1}+\theta_{3}\right)}, \theta_{3} \mid \mathrm{T}_{1}, \mathrm{~T}_{2}, \mathrm{~T}_{3}\right) \times|J|
$$

with $J$ the Jacobian of the transformation from $\left(\theta_{1}, \theta_{2}, \theta_{3}\right)$ to $\left(\theta_{1}, A_{\infty}, \theta_{3}\right)$.

For the joint posterior distribution (10) the marginal posterior distribution for $A_{\infty}$ is obtained by using the Gibbs sampling method (Gelman et al, 1995). The Gibbs sampler allows the generation of a sample from the following full conditional distributions

$$
\begin{aligned}
& g\left(\theta_{1} \mid \text { data, } \theta_{2}, \theta_{3}\right) \\
& g\left(\theta_{2} \mid \text { data, } \theta_{1}, \theta_{3}\right) \\
& g\left(\theta_{3} \mid \text { data, } \theta_{1}, \theta_{2}\right)
\end{aligned}
$$

These conditional distributions are used in the iterative scheme to generate samples for each of the three marginal distributions and subsequently of $A_{\infty}$ using (4).

\section{NUMERICAL ILLUSTRATION}

To illustrate the results in section 3, exponentially distributed samples were simulated for the three variables in the system. Table 2 gives the sample information for sample sizes of 40 and 200 , respectively.

\section{Table 2 Sample summary}

\begin{tabular}{|c|r|r|r|r|r|r|}
\hline & \multicolumn{3}{|c|}{$n=40$} & \multicolumn{3}{c|}{$n=200$} \\
& \multicolumn{1}{|c|}{$X$} & \multicolumn{1}{c|}{$Z$} & \multicolumn{1}{c|}{$X$} & \multicolumn{1}{c|}{$Z$} \\
\hline Mean & 636.05 & 193.84 & 41.34 & 505.59 & 192.41 & 50.59 \\
\hline st. dev. & 873.26 & 177.64 & 44.48 & 481.85 & 172.19 & 54.74 \\
\hline sum & 25442.17 & 77.62 & 1653.69 & 101119.00 & 38481.16 & 10117.97 \\
\hline
\end{tabular}

The full conditionals (10) are simulated with WINBUGS software, using the Gibbs sampling method. Initial burn-in samples of a 1000 were first simulated for the model, which was followed by 10000 iterations of this procedure to simulate the marginal distribution of $A_{\infty}$. Table 3 and 4 show the posterior mean, median and the $(1-\alpha)$ $100 \%$ HPD intervals for $A_{\infty}$, for sample with sizes 40 and 200 , respectively. In both the tables the estimates were obtained for different values of the parameter $p$. 
Table 3 Posterior mean, median and HPD intervals for $A_{\infty}(n=40)$

\begin{tabular}{|c|c|c|c|c|c|c|}
\hline$p$ & $\begin{array}{c}\text { post. } \\
\text { Mean }\end{array}$ & St. dev. & median & $\mathbf{9 5 \% ~ H P D}$ & $\mathbf{9 0 \% ~ H P D}$ & $\mathbf{8 0 \% \text { HPD }}$ \\
\hline 0.00 & 0.7641 & 0.0401 & 0.7661 & $(0.6787 ; 0.8368)$ & $(0.6938 ; 0.8268)$ & $(0.7105 ; 0.8148)$ \\
\hline 0.10 & 0.7639 & 0.0407 & 0.7659 & $(0.6783 ; 0.8367)$ & $(0.6935 ; 0.8266)$ & $(0.7103 ; 0.8145)$ \\
\hline 0.33 & 0.7633 & 0.0406 & 0.7653 & $(0.6777 ; 0.8362)$ & $(0.6931 ; 0.8260)$ & $(0.7096 ; 0.8138)$ \\
\hline 0.50 & 0.7629 & 0.0407 & 0.7650 & $(0.6773 ; 0.8359)$ & $(0.6927 ; 0.8257)$ & $(0.7092 ; 0.8135)$ \\
\hline 0.67 & 0.7625 & 0.0407 & 0.7646 & $(0.6766 ; 0.8356)$ & $(0.6921 ; 0.8252)$ & $(0.7087 ; 0.8132)$ \\
\hline 0.90 & 0.7619 & 0.0409 & 0.7639 & $(0.6759 ; 0.8352)$ & $(0.6931 ; 0.8248)$ & $(0.7081 ; 0.8128)$ \\
\hline 1.00 & 0.7616 & 0.0409 & 0.7637 & $(0.6757 ; 0.8351)$ & $(0.6910 ; 0.8247)$ & $(0.7078 ; 0.8126)$ \\
\hline
\end{tabular}

Table 4 Posterior mean, median and HPD intervals for $A_{\infty}(n=200)$

\begin{tabular}{|c|c|c|c|c|c|c|}
\hline$P$ & $\begin{array}{l}\text { post. } \\
\text { Mean }\end{array}$ & St. dev. & median & 95\% HPD & $90 \%$ HPD & $80 \%$ HPD \\
\hline 0.00 & 0.7235 & 0 & 38 & $(0.6840 ; 0.7615)$ & $(0.6897 ; 0.7560)$ & $0.6974 ; 0.7489)$ \\
\hline 0.10 & 0.7230 & 0.0200 & 0.7233 & $(0.6836 ; 0.7611)$ & $(0.6892 ; 0.7555)$ & $(0.6969 ; 0.7485)$ \\
\hline 0.33 & 0.7219 & 0.0201 & 22 & $(0.6823 ; 0.7602)$ & $(0.6880 ; 0.7545)$ & $(0.6956 ; 0.7474)$ \\
\hline 0.50 & 0.7211 & 0.0201 & 0.7214 & $(0.6814 ; 0.7595)$ & $(0.6872 ; 0.7537)$ & $(0.6948 ; 0.7466)$ \\
\hline 0.67 & 0.7203 & 0.0202 & 0.7205 & $(0.6805 ; 0.7589)$ & $(0.6863 ; 0.7530)$ & $(0.6940 ; 0.7459)$ \\
\hline 0.90 & 0.7192 & 0.0202 & 0.7194 & $(0.6794 ; 0.7580)$ & $(0.6851 ; 0.7520)$ & $(0.6927 ; 0.7448)$ \\
\hline 1.00 & 0.7187 & 0.0202 & 0.7189 & $(0.6789 ; 0.7576)$ & $(0.6846 ; 0.7516)$ & $(0.6922 ; 0.7444)$ \\
\hline
\end{tabular}

From these tables it is evident that when the parameter $p$ decreases, the estimates of $A_{\infty}$ increases. It is also evident that the influence of the parameter $p$ is minimal in this illustration. The differences of the largest and the smallest estimates of $A_{\infty}$ are all less than 0.005 . Figures 2 and 3 shows the posterior distribution for $A_{\infty}$, with $p=0.33$, for the samples of size 40 and 200 , respectively.

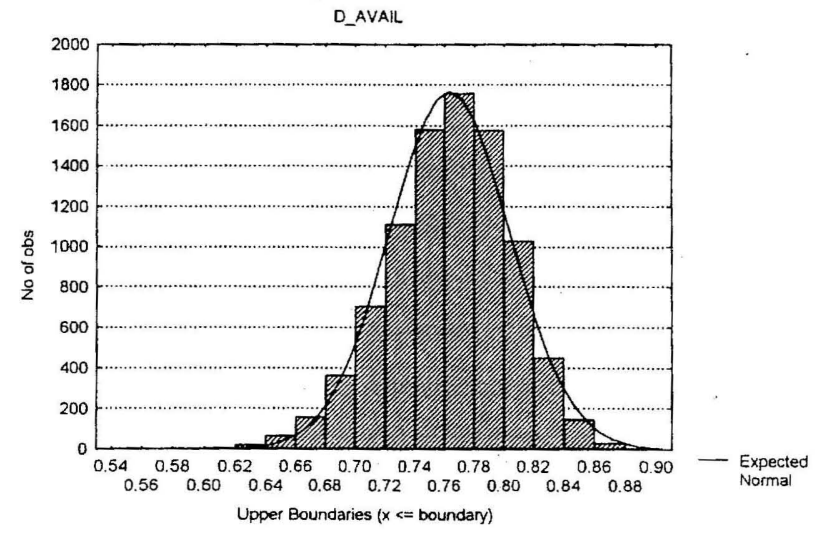

Figure 2 Posterior distribution for $A_{\infty}(n=40)$ 


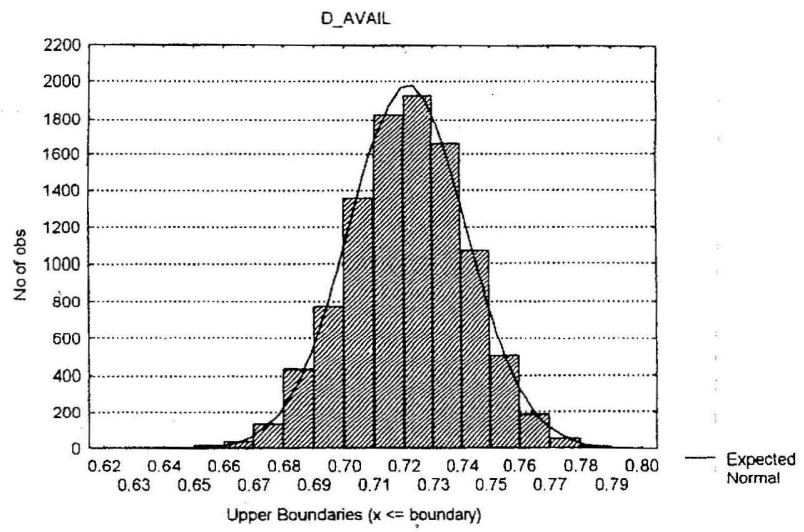

Figure 3 Posterior distribution for $A_{\infty}(n=200)$

The posterior distribution for $A_{\infty}$ will vary most when large rest times are observed in a system (see term $p \theta_{3}^{2}$ in expression (4) for $A_{\infty}$ ). It is clear in this case for large probability $p$, that the estimates for $A_{\infty}$ will dramatically decrease, relative to smaller failure and repair times.

\section{REFERENCES}

[1] Bernardo, J.M. \& Smith, A.F.M. (2000). Bayesian Theory. New York: Wiley \& Sons.

[2] Box, G.E.P. \& Tiao, G.C. (1992). Bayesian inference in Statistical Analysis. New York: Wiley \& Sons.

[3] Brender, D.M. (1968, a). The prediction and measurement of system availability: A Bayesian Statement, IEEE Trans. Rel., R-17, pp 127-138.

[4] Brender, D.M. (1968, b). The Bayesian assessment of availability: Advanced applications and techniques, IEEE Trans. Rel., R-17, pp 138 - 147.

[5] Gelman, A., Carlin, J.B., Stern, H.S. \& Rubin, D.B. (1995). Bayesian Data Analysis, New York: Chapman \& Hall.

[6] Kapur, K.C. \& Lamberson, L.R. (1977). Reliability in Engineering design, New York: Wiley \& Sons.

[7] Klassen, B. \& Van Peppen, J.C.L. (1989). System reliability: concepts and applications, New York: Edward Arnold.

[8] Kumar, A. \& Agarwal, M.L. (1980). A review of standby systems. IEEE Trans. Rel., R-29, 290-294. 
[9] Lie, C.H., Hwang, C.L. \& Tillman, F.A. (1977). Availability of maintained systems: A state-of-the-art survey, AIEE Trans. R-9, pp 247-259.

[10] Martz, H.F. \& Waller, R.A. (1982), Bayesian reliability analysis. New York: Wiley \& Sons.

[11] Pham-Gia, T. \& Turkkan, N. (1999). System availability in a Gamma alternating renewal process, Nav. Res. Log, Quantify, vol 46, pp 822-844.

[12] Ravindran, A., Phillips, D.J. \& Solberg, J.J. (1987). Operations research principles and practice, New York: Wiley \& Sons.

[13] Subramanian, R. \& Sarma, Y.V.S. (1981). A Standby System with 'dead time' for the repair facility, IEEE Trans. Rel., R-30, p 498.

[14] Yadavalli, V.S.S., Botha, M. \& Bekker, A. (2001). Confidence limits for the steady state availability of a system with a 'rest-period' for the repair facility. Submitted to Engineering Simulation. 